\title{
HUBUNGAN BELIEVING DAN BELONGING SEBAGAI DIMENSI RELIGIUSITAS DENGAN LIMA DIMENSI WELL-BEING PADA MAHASISWA DI TANGERANG
}

\author{
Andy Saputra, \\ Yonathan Aditya Goei, \\ Sri Lanawati \\ Fakultas Psikologi \\ Universitas Pelita Harapan \\ Jl. MH. Thamrin Boulevard, Lippo Karawaci, \\ Tangerang 15811, Indonesia \\ e-mail ${ }^{1}$ :andy.saputra1994@gmail.com
}

\begin{abstract}
Recent studies showed that well-being has been decreasing in both Asia and the United States of America. Another study found that college students' well-being was also declining. These findings suggest that ways to increase well-being become very crucial to be explored, such as exploring what variables that correlates or affect it. Previous findings found that religiosity, specifically believing and belonging dimension, affects well-being. This study explore how believing and belonging correlates with wellbeing and its five dimensions, positive emotions, engagement, positive relationships, meaning, and accomplishment among 181 college students. The result shows that both believing and belonging correlates with the five dimensions of well-being significantly, meaning that the belief in God and belonging into religious groups helps individual's well-being to flourish.
\end{abstract}

Keywords: well-being; religiosity; Christianity

\begin{abstract}
Abstrak - Studi-studi menemukan bahwa tingkat well-being di Asia dan Amerika Serikat dan juga pada mahasiswa menurun. Penemuan-penemuan ini menunjukkan bahwa cara-cara untuk meningkatkan kesejahteraan psikologis (well-being) seseorang menjadi krusial untuk ditemukan, seperti mengeksplorasi variabel apakah yang dapat berkorelasi atau mempengaruhinya. Studi sebelumnya menemukan bahwa religiusitas, lebih spesifiknya dimensi believing dan belonging, berpengaruh secara signifikan terhadap well-being. Studi ini bertujuan untuk mengetahui bagaimana believing dan belonging berkorelasi dengan well-being dan dimensi-dimensinya, yaitu positive emotions, engagement, positive relationships, meaning, and accomplishment pada 181 mahasiswa. Hasil menunjukkan bahwa believing dan belonging berkorelasi secara signifikan dengan lima dimensi well-being, sehingga kepercayaan seseorang kepada Tuhan dan keterlibatannya dengan kelompok religius membantu meningkatkan kesejahteraan psikologisnya.
\end{abstract}

Kata kunci: kesejahteraan psikologi; religiusitas; Kristen 


\section{PENDAHULUAN}

Well-being merupakan kesejahteraan atau pengalaman individu yang positif (Ryan \& Deci, 2001). Studi mengenai tingkat well-being menunjukan bahwa hanya $14 \%$ populasi di Asia memiliki tingkat well-being yang baik (Standish \& Witters, 2013). Rendahnya tingkat well-being sering dikaitkan dengan stres, gejala depresi, dan kecemasan (Casey, 2013). Sementara well-being yang tinggi berkaitan dengan kebahagiaan dan juga kepuasan hidup yang tinggi (Tamir \& Ford, 2012). Sehingga, sangat penting untuk mempelajari tentang well-being dan mencari solusi untuk meningkatkannya.

Tingkat well-being pada populasi mahasiswa di Amerika Serikat juga ditemukan menurun (Eagan, Stolzenberg, Ramirez, Aragon, Suchard, \& Hurtado, 2014). Telah dibahas bahwa tingkat well-being yang rendah berkaitan dengan stres, gejala depresi, dan kecemasan. Hal tersebut dapat menghambat potensi mahasiswa untuk mendapatkan pencapaian akademik yang optimal. Salah satu universitas di Tangerang juga menghadapi situasi yang serupa karena ditemukan bahwa cukup banyak mahasiswa yang memiliki tingkat well-being yang rendah (anonim, komunikasi personal, 26 Februari 2015). Myers dan DeWall (2015) menemukan juga bahwa individu yang lebih berbahagia cenderung untuk memiliki masa depan yang lebih sukses. Dengan demikian, bukti-bukti ini meningkatkan urgensi penelitian tentang well-being di kalangan mahasiswa.

Terdapat beberapa variabel yang dapat mempengaruhi well-being seperti kepribadian (Steel, Schmidt, \& Shultz, 2008), umur, jenis kelamin, budaya, religiusitas, status pernikahan, dan pendapatan (Pavot \& Diener, 2013). Beberapa studi sebelumnya menemukan bahwa religiusitas memiliki korelasi positif dengan well-being, sehingga individu yang lebih religius ditemukan lebih berbahagia dan lebih puas terhadap hidupnya (Diener, Suh, Lucas, \& Smith, 1999; Cohen \& Johnson, 2011). Religiusitas dapat mempengaruhi well-being individu pada pandangan terhadap dunia dan bagaimana cara menyesuaikan diri, seperti yang ditemukan oleh Ysseldyk, Matheson, dan Anisman (2010) bahwa individu yang lebih religius percaya akan sosok Tuhan yang dapat menolong mereka ketika berada dalam masalah. Kepercayaan tersebut akan mengubah cara individu bereaksi terhadap suatu masalah yang dihadapi jika dibandingkan dengan individu yang tidak religius.

Religiusitas merupakan perbedaan individu dalam ketertarikannya terhadap suatu agama yang termasuk sikap, pemikiran, emosi dan perilaku individu tersebut (Hayward \& Krause, 2014). Saroglou (2011) membagi religiusitas menjadi empat dimensi yaitu believing, belonging, behaving 
dan bonding. Pada penelitian sebelumnya, ditemukan bahwa hanya believing dan belonging yang berpengaruh secara signifikan terhadap well-being (Saputra, Aditya, Lanawati, 2015). Hasil dari penelitian sebelumnya memicu penelitian ini untuk menjelaskan bagaimana believing dan belonging sebagai dimensi religiusitas berhubungan terhadap well-being; dan pada dimensi wellbeing yang mana kah believing dan belonging berhubungan.

\section{Religiusitas}

Religiusitas merupakan variabel yang dapat didefinisikan sebagai ketertarikan individu dan keterlibatannya pada suatu agama (Saroglou, 2014). Spiritualitas, yang merupakan suatu konstruk yang sering dibandingkan dengan religiusitas, bersifat lebih general tanpa perlu berkaitan dengan suatu agama atau sosok Tuhan (Koenig, 2005), namun Sarologou (2011) menjelaskan bahwa spiritualitas dapat dijelaskan dari definisi religiusitas juga berdasarkan kepercayaan kepada Tuhan dan juga hubungan intim dengan Tuhan tersebut.

Empat dimensi religiusitas yang dikategorikan oleh Saroglou (2011) berdasarkan beberapa studi mengenai konstruk religiusitas yang lalu adalah: believing, yaitu dimensi yang paling mendasar dari religiusitas karena dimensi tersebut menjelaskan kepercayaan individu terhadap sosok transenden dalam agamanya; belonging, menjelaskan keterlibatan individu terhadap suatu komunitas atau kelompok religius; behaving menjelaskan perilaku moral yang dilakukan oleh individu yang diajarkan oleh suatu agama; dan bonding menjelaskan relasi intim individu dengan Tuhan yang dipercayainya.

\section{Well-being}

Well-being menjelaskan kesejahteraan atau pengalaman positif manusia (Ryan \& Deci, 2001). Konstruk well-being telah dipelajari sejak zaman Yunani kuno yang terbagi menjadi dua yaitu, hedonic well-being yang merupakan perasaan gembira dan eudaimonic well-being yang bersifat lebih kompleks, menjelaskan kebahagiaan tidak hanya datang dari perasaan senang, tetapi dapat datang dari berbagai hal lainnya (Grenville-Cleave, 2012). Seligman (2011), menjelaskan well-being berdasarkan dari definisi eudaimonic well-being dan definisinya mencakup seberapa bahagia individu, seberapa engaged individu dengan hidupnya, sejauh mana individu memiliki hubungan yang positif dengan orang lain, apakah individu memiliki makna hidup, dan sebanyak apakah pencapaian yang dapat membanggakan diri individu tersebut.

Seligman (2011), juga mengategorikan well-being berdasarkan lima dimensi yaitu, positive emotion, engagement, positive relationships, meaning dan accomplishment. Positive emotion 
menjelaskan perasaan senang atau bahagia yang bersifat sementara. Engagement atau flow merupakan pengalaman pribadi yang kompleks ketika seseorang sangat fokus dengan kegiatannya sampai melupakan waktu yang membutuhkan kemampuan individu yang setara dengan tantangan yang dihadapi dalam aktivitas tersebut. Positive relationships terjalin ketka individu memiliki relasi yang intim, bahagia, dan saling mendukung dengan orang lain. Meaning menjelaskan makna hidup individu yang ditekuni yang mendorong dirinya untuk bertumbuh. Accomplishment adalah pencapaian-pencapaian yang telah dicapai oleh individu yang membuat dirinya puas dan bangga.

\section{Hubungan antara Religiusitas dengan Well-being pada Mahasiswa Kristen}

Dalam dimensi believing, individu akan membuat dirinya percaya kepada Tuhan yang Maha Kuat, menciptakan manusia untuk mencapai suatu tujuan. Kepercayaan ini dapat membuat individu memiliki makna hidup karena memiliki pandangan bahwa hidupnya memiliki tujuan yang diberikan oleh Tuhan dan tidak merupakan sebuah kebetulan saja. Kepercayaan ini dapat meningkatkan aspek meaning dari well-being (Koenig, 2005; Mattis, 2002). Individu yang menunjukkan skor pada aspek believing yang dominan akan cenderung berusaha keras untuk mencapai tujuan yang diberikan oleh Tuhan. Hal ini akan mendorong individu untuk berada pada proses untuk mencapai tujuan transenden (Tuhan) yang memiliki tantangan dan individu juga akan merasa mampu karena sadar bahwa Tuhan akan memberikan kekuatan, sehingga dapat membuat individu dalam kondisi flow (Primeaux \& Vega, 2002). Believing juga dapat mendorong individu untuk mencapai prestasi dalam hidupnya. Dalam penelitian Jeynes (2007) ditemukan bahwa individu yang memiliki tingkat believing yang meningkat melalui pengajaran dari sekolah akan cenderung memiliki prestasi yang meningkat pula. Hal tersebut juga dapat dilihat ketika individu bekerja keras dan dapat mencapai tujuan yang diberikan Tuhan, tingkat accomplishment akan meningkat. Secara spesifik menurut Kekristenan, penderitaan dan kesulitan merupakan bagian dari kehidupan di dunia yang telah jatuh dalam dosa, tetapi ada Tuhan yang berjanji untuk menyertai mereka dalam menjalani hidup mereka dan Tuhan berjanji akan membuat segala sesuatu menjadi lebih baik di dunia ini atau di dunia yang akan datang. Individu yang dapat mengerti dan menerima pandangan religius dalam menghadapi situasi sulit yang sedang dialami akan cenderung memiliki tingkat positive emotion yang lebih stabil walau berada dalam masa yang sulit, sehingga individu akan tidak berputus asa dan memiliki tingkat well-being yang baik (Koenig, 2005).

Belonging individu akan membantunya untuk mendapat dukungan. Dukungan dari keluarga dan teman-teman sangat membantu ketika manusia sedang mengalami kesulitan (Koenig, 2005). Individu yang religius biasanya memiliki komunitas religius pula yang dapat membantu dan 
mendukung individu tersebut dalam menghadapi kesulitan, serta dapat mengurangi tingkat stres (positive emotion) dan membuat individu tersebut tidak merasa terisolasi (Krause, 2002). Dengan demikian, individu akan memiliki tingkat positive relationship dalam well-being yang tinggi karena individu dapat menjalin relasi yang dekat dengan individu lain oleh karena hubungan religiusitasnya.

\section{METODE}

\section{Partisipan}

Partisipan penelitian ini sebanyak 181 yang merupakan mahasiswa Fakultas Psikologi dan Fakultas Ilmu Pendidikan angkatan 2013 dan 2015 yang beragama Kristen di salah satu universitas di Tangerang. Rentang umur partisipan berkisar dari 17 tahun sampai 25 tahun.

\section{Desain}

Penelitian ini menggunakan metode kuantitatif untuk mengukur variabel religiusitas dan well-being karena metode kuantitatif merupakan metode ilmiah yang bersifat empiris, obyektif, terukur, rasional, dan sistematis (Sugiyono, 2008). Desain penelitian ini bersifat non-eksperimental karena dalam penelitian ini tidak menggunakan teknik manipulasi pada independen variabel (Gravetter \& Forzano, 2009).

\section{Prosedur}

Peneliti membagikan kuesioner kepada partisipan sesuai dengan kriteria-kriteria yang telah ditentukan seusai kelas-kelas yang diikuti oleh mahasiswa. Dari sebanyak 195 kuesioner yang dibagikan, sebanyak 181 data dapat digunakan yang telah diisi dengan lengkap.

Alat ukur yang digunakan adalah The Four Basic Dimensions of Religiousness scale (Saroglou, 2011) untuk mengukur religiusitas dan The PERMA-Profiler: A Brief Measure of Flourishing (Butler \& Kern, 2013) untuk mengukur well-being. The Four Basic Dimensions of Religiousness scale (Saroglou, 2011) memiliki 12 butir dan hasil adaptasi alat ukur tersebut menghasilkan nilai Cronbach's Alpha sebesar .89 dan corrected item-total correlation sebesar .45 .73. Alat ukur The PERMA-Profiler: A Brief Measure of Flourishing (Butler \& Kern, 2013) memiliki 16 butir dan hasil adaptasi alat ukur tersebut menghasilkan nilai Cronbach's Alpha sebesar .92 dan corrected item-total correlation sebesar .34- .85. 


\section{Teknik Analisis}

Pengolahan data dalam penelitian ini menggunakan Statistical Package for Social Sciences (SPSS) versi 22. Peneliti melakukan uji validitas dan reliabilitas alat ukur religiusitas dan wellbeing yang telah diadaptasi. Selanjutnya peneliti melakukan uji normalitas menggunakan nilai skewness dan kurtosis dan menemukan bahwa data berdistribusi normal, sehingga peneliti dapat melanjutkan untuk melihat hubungan menggunakan teknik statistik korelasi Pearson antara dimensi believing dan belonging dari variabel religiusitas dengan dimensi positive emotion, engagement, positive relationships, meaning dan accomplishment dari variabel well-being.

\section{ANALISIS DAN HASIL}

Dari 181 partisipan yang berpartisipasi dalam penelitian ini, diketahui 62 orang di antaranya berjenis kelamin laki-laki. Rata-rata usia partisipan ialah 19 tahun ( $\mathrm{SD}=1.35$ ). Lalu peneliti melakukan uji korelasi Pearson pada dimensi believing dan belonging dengan positive emotion, engagement, positive relationships, meaning dan accomplishment. Hasil menunjukkan bahwa believing dan belonging berhubungan secara signifikan dengan kelima dimensi well-being ( $p<.05)$.

Hasil analisis menunjukkan bahwa believing berkorelasi secara signifikan dengan positive emotion ( $r=.172, p=.020)$, engagement $(r=.316, p=.000)$, positive relationships $(r=.160, p=.031)$, meaning $(r=.184, p=.013)$ dan accomplishment $(r=.263, p=.000)$. Belonging berkorelasi secara signifikan dengan positive emotion ( $r=.188, p=.011$ ), engagement ( $r=.164, p=.028)$, positive relationships ( $r=.190, p=.010)$, meaning ( $r=.309, p=.000)$ dan accomplishment $(r=.292, p=.000)$.

\section{DISKUSI}

Hasil analisa menunjukkan bahwa terdapat hubungan yang signifikan antara believing dan belonging dengan positive emotion, engagement, positive relationships, meaning, dan accomplishment. Hasil tersebut mendukung penelitian-penelitian sebelumnya bahwa religiusitas berhubungan secara signifikan dengan well-being dan terlihat lebih spesifik dalam dimensi-dimensi kedua variabel tersebut.

Believing yang berhubungan secara signifikan dengan positive emotion, menjelaskan bahwa individu yang percaya kepada Tuhan akan cenderung merasa lebih tenang ketika menghadapi situasi yang sulit (Koenig, 2005). Individu akan mengerti bahwa penderitaan merupakan bagian dari 
hidup, tetapi juga mengetahui bahwa Tuhan dapat membuat segala sesuatu menjadi lebih baik pada waktunya, sehingga membuat individu lebih merasa tenang. Individu juga akan percaya bahwa hidupnya diciptakan oleh Tuhan untuk suatu tujuan, sehingga membuatnya untuk memiliki makna hidup dan mengetahui bahwa hidupnya bukan hanya kebetulan saja yang meningkatkan meaning individu (Koenig, 2005; Mattis, 2002). Ketika individu mengerti akan tujuan yang diberikan oleh Tuhan, maka individu akan berusaha keras untuk mencapai tujuan tersebut, menciptakan proses flow atau engagement karena individu akan merasa tertantang dan di saat yang sama mengetahui bahwa Tuhan juga akan memberikan kekuatan (Primeaux \& Vega, 2002). Individu yang sadar akan tujuan yang diberikan oleh Tuhan juga akan cenderung terdorong untuk mencapai prestasi, sehingga individu dengan believing yang tinggi akan memiliki accomplishment yang tinggi pula seperti yang ditemukan oleh Jeynes (2007). Saroglou (2011) menjelaskan bahwa believing merupakan dasar dari religiusitas, sehingga believing sendiri memiliki hubungan yang erat dengan belonging. Hal tersebut dapat menjelaskan bahwa kepercayaan kepada Tuhan juga berkaitan dengan relasi yang perlu dibentuk dengan umat lain, sehingga dapat menjalin positive relationship.

Belonging dalam diri individu akan membantunya untuk mendapat dukungan. Dukungan dari keluarga dan teman-teman sangat membantu ketika manusia sedang mengalami kesulitan (Koenig, 2005). Individu yang religius biasanya memiliki komunitas religius pula yang dapat membantu dan mendukung individu tersebut dalam kesulitan yang dapat mengurangi tingkat stres (positive emotion) dan membuat individu tersebut tidak merasa terisolasi (Krause, 2002). Individu yang memiliki dukungan dari lingkungan cenderung untuk melakukan hal yang sama karena religiusitas individu akan mengajarkan individu untuk juga memperhatikan sesama umat, hal tersebut akan memberikan tantangan pada individu yang dapat meningkatkan engagement (Primeaux \& Vega, 2002). Perilaku saling mendukung dan memerhatikan akan meningkatkan meaning individu karena individu akan sadar bahwa dia berguna ketika membantu individu lain (Hainsworth \& Barlow, 2001). Individu yang memiliki tujuan untuk membantu individu lain akan cenderung untuk mengabdikan hidupnya pada tujuan tersebut dan ketika individu telah membantu banyak orang, tentu dia akan dapat melihatnya sebagai suatu pencapaian, sehingga meningkatkan accomplishment. 


\section{SIMPULAN DAN SARAN}

\section{Simpulan}

Berdasarkan hasil dari penelitian ini, believing dan belonging berkorelasi secara signifikan dengan lima dimensi well-being yaitu, positive emotion, engagement, positive relationship, meaning, dan accomplishment pada mahasiswa Kristen. Hal tersebut dapat menjelaskan bahwa secara keseluruhan, kepercayaan individu terhadap Tuhan, pengetahuannya tentang Tuhan, dan keterlibatannya dengan suatu komunitas atau kelompok religius berperan penting dalam well-being seseorang.

\section{Saran Teoretis}

Saran untuk penelitian selanjutnya adalah dapat mengambil sampel yang lebih luas, mencakup beragam agama di Indonesia agar dapat melihat perbedaan interaksi variabel pada sampel dengan agama yang berbeda. Hal ini juga dapat menjawab apakah agama tertentu lebih berpengaruh terhadap well-being atau apakah terdapat perbedaan dimensi religiusitas yang mempengaruhi well-being.

\section{Saran Praktis}

Saran untuk masyarakat adalah untuk lebih menekuni religiusitas masing-masing, tidak hanya karena dorongan lingkungan, tetapi perlu untuk meyakininya dengan baik karena, seperti yang ditunjukkan oleh hasil dalam penelitian ini, kepercayaan individu terhadap Tuhan dapat meningkatkan well-being atau kesejahteraan. Hal ini dapat dilakukan dengan cara membaca buku religius, melakukan refleksi terhadap buku yang dibaca, dan mencoba untuk menjalin relasi yang baik dengan Tuhan yang dipercayai. Masyarakat juga perlu mendorong diri sendiri untuk membuat atau berpartisipasi dalam kelompok-kelompok rohani agar dapat mendiskusikan bacaan dan di saat yang sama dapat saling memberikan dukungan rohani juga yang ditemukan meningkatkan wellbeing.

\section{REFERENSI}

Butler, J. \& Kern, M. L. (2013). The PERMA-Profiler: A Brief Measure of Flourishing. University of Pennsylvania: Philadelphia. 
Casey, L. (2013). Stress and wellbeing in Australia survey 2013. Ditemu kembali dari https://www.psychology.org.au/Assets/Files/Stress\%20and\%20wellbeing\%20in\%20Australi a\%20survey\%202013.pdf

Cohen, A. B. \& Johnson, K. A (2011). Religion and Well-being. Naskah dipresentasikan pada Yale Center for Faith and Culture consutation of Happiness and Human Flourishing tanggal 910 Desember 2011. Ditemu kembali dari http://faith.yale.edu/sites/default/files/cohen_and_johnson_0.pdf

Diener, E., Suh, E. M., Lucas, R. E., \& Smith, H. L. (1999). Subjective well-being: three decades of progress. Psychological Bulletin, 125(2), 276-302. Ditemu kembali dari http://cinik.free.fr/chlo/doc\%20dans\%20biblio,\%20non\%20imprim\%C3\%A9s/subjective\%2 0well\%20being.pdf

Eagan, K., Stolzenberg, E. B., Ramirez, J. J., Aragon, M. C., Suchard, M. R., \& Hurtado, S. (2014). The American freshman: National norms fall 2014. Higher Education Research Institute, UCLA. Ditemu kembali dari https://www.heri.ucla.edu/monographs/TheAmericanFreshman2014-Expanded.pdf

Gravetter, F., \& Forzano, L. (2009). Research methods for the behavioral sciences. Belmont, CA: Wadsworth Cenage Learning.

Grenville-Cleave, B. (2012). Positive psychology. London: Icon Books.

Hayward, R. D. \& Krause, N. (2014). Religion, mental health and well-being: Social aspects. Dalam V. Saroglou (Ed.), Religion, Personality, and Social Behavior (pp. 255-280). New York, NY: Psychology Press.

Hainswort, J., \& Barlow, J. H. (2001). Volunteers' experiences of becoming an arthritis selfmanagement lay-leader: 'It's almost as if I've stopped ageing and started to get younger!'. Arthritis Care and Research, 45, 378-383.

Jeynes, W. H. (2007). Religion, intact families, and the achievement gap. Interdisciplinary Journal of Research on Religion, 3, 1-23. Ditemu kembali dari http://www.religjournal.com/pdf/ijrr03003.pdf

Koenig, H. (2005). Faith and mental health. Radnor, PA: Templeton Foundation Press.

Krause, N. (2002). Church-based social support and health in old age: Exploring variations by race. The Journals Of Gerontology Series B: Psychological Sciences And Social Sciences, 57(6), S332-S347. doi:10.1093/geronb/57.6.s332 
Mattis, J. (2002). Religion and spirituality in the meaning-making and coping experiences of african american women: A qualitative analysis. Psychology Of Women Quarterly, 26(4), 309-321. doi:10.1111/1471-6402.t01-2-00070

Myers, D., \& DeWall, C. N. (2015). Psychology (11th ed.). New York, NY: Worth Publishers.

Pavot, W., \& Diener, E. (2013). Happiness Experienced: The Science of Subjective Well-being. Dalam S. David, I. Boniwell \& A. Ayers, The Oxford Handbook of Happiness ( $1^{\text {st }}$ ed.). Oxford, U.K.: Oxford University Press.

Primeaux, P., \& Vega, G. (2002). Operationalizing Maslow: religion and flow as business partners. Journal Of Business Ethics, 38(1/2), 97-108. doi:10.1023/a:1015733332183

Ryan, R., \& Deci, E. (2001). On happiness and human potentials: A review of research on hedonic and eudaimonic well-being. Annual Review Psychology, 52(1), 141-166. doi:10.1146/annurev.psych.52.1.141

Saputra, A., Aditya, Y., \& Lanawati, S. (2015). The effects of religiosity on the well-being of college students. Naskah dipresentasikan pada International Conference Psychology, Psychological Transformation Towards Developing Characterized Human Being pada tanggal 16 Oktober 2015 di Semarang, Indonesia.

Saroglou, V. (2011). Believing, Bonding, Behaving, and Belonging: The Big Four Religious Dimensions and Cultural Variation. Journal Of Cross-Cultural Psychology, $\quad 42(8)$, 1320-1340. doi:10.1177/0022022111412267

Saroglou, V. (2014). Religion, Personality, and Social Behavior. New York, NY: Taylor \& Francis. Seligman, M. (2011). Flourish. New York, NY: Free Press.

Standish, M., \& Witters, D. (2013). Country Well-being Varies Greatly Worldwide. Ditemu kembali dari Gallup: http://www.gallup.com/poll/175694/country-varies-greatlyworldwide.aspx

Steel, P., Schmidt, J., \& Shultz, J. (2008). Refining the relationship between personality and subjective well-being. Psychological Bulletin, 134(1), 138-161. doi:10.1037/00332909.134.1.138

Sugiyono. (2008). Metode penelitian pendidikan: Pendekatan kuantitatif, kualitatif dan $R \&$ D. Bandung: Alfabeta.

Tamir, M., \& Ford, B. (2012). Should people pursue feelings that feel good or feelings that do good? Emotional preferences and well-being. Emotion, 12(5), 1061-1070. doi:10.1037/a0027223 
Ysseldyk, R., Matheson, K., \& Anisman, H. (2010). Religiosity as identity: Toward an understanding of religion from a social identity perspective. Personality And Social Psychology Review, 12(1), 60-71. doi:10.1177/1088868309349693 